定常状態コンプライアンスの濃度依存性*

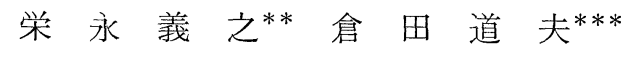 \\ 杉江勉****田村幹 雄****

\section{The Concentration Dependence of Steady-State Compliance for Polymer Solutions}

by

\author{
Yoshiyuki EinaGA, Michio Kurata \\ (Institute for Chemical Research, Kyoto University, Uji) \\ Tsutomu SUGIE and Mikio TAMURA \\ (Faculty of Engineering, Kyoto University, Kyoto)
}

The steady-state compliance $J_{e}$ as a function of the molecular weight $M$ and the concentration $c$ for polymer solution can be expressed as:

$$
\begin{aligned}
J_{e} & =\alpha M / c R T & & \text { for smaller values of } c \text { or } M \\
& =\beta M^{0} / c^{2 \sim 3} & & \text { for larger values of } c \text { and } M
\end{aligned}
$$

Here $\alpha$ and $\beta$ are constants and $R T$ is used in its usual meaning. The second behavior of $J_{e}$ is characteristic of highly entangled system. In the concentration range where the transition from the first to the second behavior occurs, the $J_{e}$ displays the maximum.

Either of the two relaxation spectra, $A$ and $B$, are found to be compatible with these observed behaviors of $J_{e}$. These are :

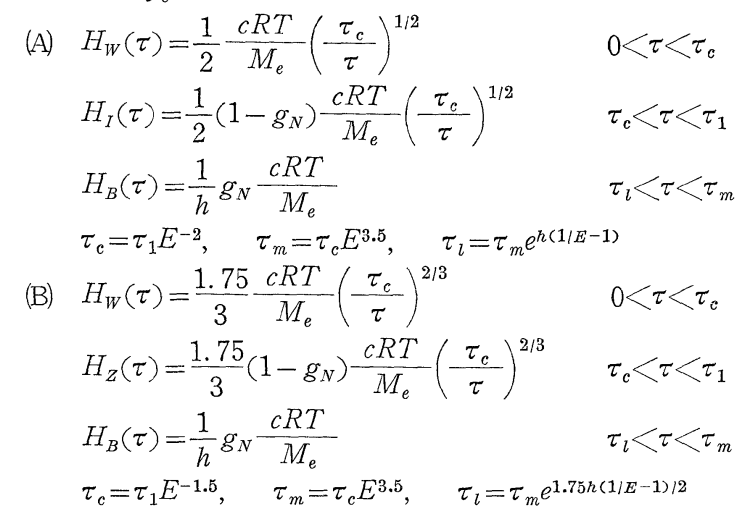

The former corresponds to the Rouse theory, while the latter to the Zimm theory. Here, $\tau_{1}$ represents the maximum relaxation time of the original Rouse or Zimm theory, $M_{e}$ is entanglement spacing, $E$ is the number of entanglement point in a molecule, hence $E=M / M_{e}$, and $g_{N}$ and $h$ are parameters representing the intensities of $H_{I}$ and $H_{B}$, respectively.

The viscosity $\eta$, storage modulus $G^{\prime}$ and loss modulus $G^{\prime \prime}$ are also calculated on the basis of these spectra. These results are qualitatively in agreement with the observed one, particularly in the case of high value of $h$ and low value of $g_{N}$.

(Recerved Jan. 29, 1972)

\section{1 序論}

高分子溶液の遅い緩和挙動すなわち, 流動領域にお

* 原稿受理 昭和47年1月29日

** 京都大学化学研究所 宇治市五个庄

*** 正会員 京都大学化学研究所 宇冶市五个生

**** 京都大学工学部 京都市左京区吉田本町
ける緩和挙動は粘度 $\eta$, 定常状態コンプライアンス $J_{e}$, 最長緩和時間 $\tau_{m}$ などによって記述することができる. 従来, これらのパラメータの分子量依存性, 濃度依存 性に関して多くの実験的研究がなされ，すでにかなり 多くのデータが集積されている。 これらの結果から, 
各パラメータの分子量依存性, 濃度依存性の特徴をあ げると次のようになる。まずクに関して，分子鎖のか らみ合いが生じ始める臨界分子量を $M_{c}$ とすると，(a) $M<M_{c}$ の場合, $\eta=A M$, (b) $M>M_{c}$ の場合, $\eta=$ $B M^{3.5}$, (c) $M>M_{c}$ の場合, $\eta / \zeta=D c^{3.55}$, (d) 濃度が低 下するにつれて、クは(a)から(b)の領域へ $M$ とともにゆ るやかに変化するよらになる。 $J_{e}$ に関して, (e) $M<$ $M_{c}$ の場合, $J_{e}=\alpha M / c R T^{4)}$, (f) $M \gg M_{c}$ の場合, $J_{e}=$ $\beta M^{\circ} / c^{2-3)}$, (g) $J_{e}$ の分子量依存性飞関して，J $J_{e}$ が分子

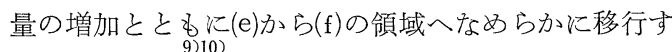
るデータはあるが，この点はまだ定かでない（（h） $J_{e}$ は濃度の増加とともに(e)から(f)の領域へ移行するが, $M$ が $M_{c}$ に達する臨界濃度付近に沶いて, $J_{e}$ は濃度 に対して極大值を通過することが，最近クリープ測定 および流動復屈折が測㫌より見いだされている。 に関して, (1) $M>M_{c}$ の場合, $\tau_{m} \propto M^{7.83}$. ここで $A$, $B, D, \alpha, \beta$ は定数, $M$ は分子量, $c$ は濃度, $\zeta$ はセ グメント摩擦保数, Rはガス定数, $T$ は温度である.

以上の実験事実を充分に説明しらる理論はまだない が，半経験的に上記のいくつかが記述を試みた例があ る.たとえば $J_{e}$ の分子量, 濃度依存性に関して Graessley と Segal は次の式を提案した。

$$
J_{e}=\frac{\alpha}{1+\gamma c M} \frac{M}{c R T} \quad \gamma \text {; 定数 }
$$

この式は(e)，(f)の事実によく一致し，(g)の結果を比較 的よく表わすが， $J_{e}$ は濃度とともに除々に(e)から(f)の 領域へ移ることになり（）の結果は記述しえない。 た Janeschitz-Krieg1 は Rouse 理論による緩和スぺ クトルの末端部を長時間方向に切り離した。いわ的る 修正 Rouse 理論と類似の計算を行ない, 換算定常状態 コンプライアンス, $J_{e} c R T / M$ が臨界濃度, 臨界分子 量付近で極大をもつことを示した。この結果は(h)をよ く表わしているものと考光られるが，(f)が事実とは一 致し光ない.

この報告では，いかなる緩和スペクトルを設定すれ ば上記の実験事実，特に(h)の結果を現象論的に解釈す ることができるかの考察を行なうことにする。

\section{2 緩和スペクトル}

高分子濃厚溶液の種々の粘弾性関数には短時間側か ら順に, 転移領域, ゴム状平坦領域拈よび流動領域と 分類できる特徽的な各領域が存在することが知られて 特り，転移領域を表わすくさび形スペクトル $H_{W}(\tau)$ と ゴム状平坦領域，流動領域を表わすスペクトル $H_{B}(\tau)$ の二つに分かれた緩和スペクトルでるってこれを記 述することもよく行なわれている。ここで設定される 緩和スペクトルは実験的に得られた粘弾性関数に矛盾 しないるのでなければならない。緩和スペクトル関 して,これまでに測定された粘弾性関数から得られる

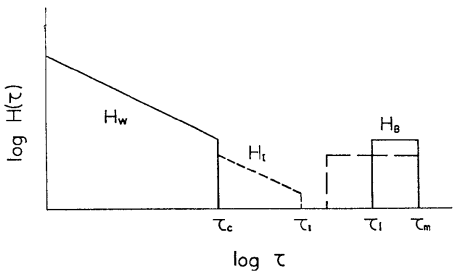

F1g 1. Relaxation spectrum.

情報として次のものが挙げられる. (j) $H_{W}(\tau)$ の高さ は濃度 $c$ に比例し, 分子量 $M$ よらない. (k) $H_{W}(\tau)$ の長時間端の時間 $\tau_{c}$ は分子量 $M$ によない. (1) $H_{B}$ ( $\tau$ ）の高さは $c^{2}$ に比例し, MVよらない. (m) 損失弾 性率 $G^{\prime \prime}(\omega)$ の周波数 $\omega$ に対する曲線でゴム状平坦領 域に極小が現われることから， $H_{W}(\tau)$ と $H_{B}(\tau)$ は離 れているか，あるいは $H_{W}(\tau)$ と $H_{B}(\tau)$ の中間に谷 の部分が存在しなければならない。

今までのところ, 緩和スペクトルの明確な形は実験 的にも，理論的にも見いだされていないので，この報 告ではFig. 1 に示した形の緩和スペクトルを仮定して 計算を進めることにする。

$H_{W}$ は粘弾性関数に特ける転移領域に対応するもの で，からみ合い点間が分子鎖の運動に基づいて生じる ものと考岳られる。したがって孤立分子に対する粘弾 性理論である Rouse 理論あるいは Zimm 理論による 緩和スペクトルを用いて表わしても大きくはまちがわ ないと考光られる。実際，後に示すようにこれらの理 論を適用した場合， $H_{W}$ のモデルは(J)の事実によく一 致する.

$H_{B}$ は粘弾性関数に扮ける流動領域怙よびゴム状平 坦領域の一部に対応するもので，分子鎖のからみ合い による網目の緩和に起因しているものと考兄られる. $H_{B}$ の形についての情報は(f)の $J_{e}$ が $M$ によらない. (i)の $\tau_{m}$ が $M^{3.5}$ 飞比例する。 といら実験事実のみで あり，これを満たすためには $H_{B}$ の長時間端， $\tau_{m}$ の 時間域での高さが $M^{0} / c^{2 \sim 3}$ に比例し, その形が $M$ K よって大きく変化しさ光しなけ机ばよい，したがって $H_{B}$ の詳細な形は不明であるが，(f)，(1)の実験事実に 合致する最も単純な形である箱形スペクトルを今回の 計算では採用する。 ${ }_{1} H_{B}$ の高さに関しては(1)の実験事 実がある。ゴム弾性論によると $H_{B}$ の高さは濃度に比 例し，から合い点間分子量 $M_{e}$ に逆比例する。すな わち，

$$
H_{B} \propto \frac{C R T}{M_{e}}
$$

と記述する事ができる。したがって $M_{e}$ が $c$ に逆比例 するものとすると(2)式は(1)によく一致する。 また箱形 スペクトルの時間軸方向の広がりは，高分子鎖の分子 運動の自由度がから久合いによらず保存され，緩和モ 
ードの数は不変であるといら考察から次式によって決 定される。

$$
\int_{\tau_{c}}^{\tau_{1}} g_{N} H_{W}(\tau) d \ln \tau=\int_{\tau_{l}}^{\tau_{m}} H_{B}(\tau) d \ln \tau
$$

この考え方は, 固体に対する比熱の理論に就いて有名 な Debye の仮定に類似したるのである.

$H_{I}$ は粘弾性関数に和けるゴム状平坦領域に対応す るもので, $M_{e}$ よりも長い自由鎖の存在の可能性を考 慮し, $H_{W}$ と $H_{B}$ の中間の時間域に何らかの形で存在 すると仮定したスペクトルである。 $H_{I}$ の形は全く不 明であるが，今回の計算では，後に示すよらに $H_{W}$ の 長時間部分がそのをまの形で何割か残るものと仮定し た。

ここで 1 分子当たりのからみ合い点の数 $E$ を次のよ らに定義する。

$$
E=\frac{M}{M_{e}}
$$

上に述べたよらに $M_{e}$ が $c$ に逆比例するものとすると, $E$ は $c$ 一定の場合 $M$ に. $M$ 一定の場合 $c$ に比例するこ とになる。

以上の考察に基づけば，Fig. 1 に示した緩和スペク トルは以下のように定式化することができる。

(A) $H_{W}(\tau)$ Rouse 理論によるスペクトルを用い た場合,

$$
\begin{aligned}
H_{W}(\tau) & =\frac{1}{2} \frac{c R T}{M_{e}}\left(\frac{\tau_{c}}{\tau}\right)^{1 / 2}, & & 0<\tau<\tau_{c} \\
H_{I}(\tau) & =\frac{1}{2}\left(1-g_{N}\right) \frac{c R T}{M_{e}}\left(\frac{\tau_{c}}{\tau}\right)^{1 / 2}, & \tau_{c}<\tau<\tau_{1} & \text { (6) } \\
H_{B}(\tau) & =\frac{1}{h} g_{N} \frac{c R T}{M_{e}}, & & \tau_{e}<\tau<\tau_{m}
\end{aligned}
$$

(B) $H_{W}(\tau)$ Zimm 理論によるスペクトルを用い た場合

$$
\begin{aligned}
& H_{W}(\tau)=\frac{1.75}{3} \frac{c R T}{M_{e}}\left(\frac{\tau_{c}}{\tau}\right)^{2 / 3}, \quad 0<\tau<\tau_{c} \\
& H_{I}(\tau)=\frac{1.75}{3} \frac{c R T}{M_{e}}\left(1-g_{N}\right)\left(\frac{\tau_{c}}{\tau}\right)^{2 / 3}, \\
& \tau_{c}<\tau<\tau_{1} \quad \text { (12) } \\
& H_{B}(\tau)=\frac{1}{h} g_{N} \frac{c R T}{M_{e}} \text {, } \\
& \tau_{c}=\tau_{1} E^{-1.5} \\
& \tau_{m}=\tau_{c} E^{3.5} \\
& \tau_{l}=\tau_{m} 1.75 h(1 / E-1) / 2
\end{aligned}
$$

(5)，(11)式は Rouse 理論あるいは Zimm 理論がから 父合い点間の分子鎖, 寸なおち $M \leq M_{e}$ の分子鎖に対
して適用することができるものとして求めたもので, それぞれの理論によるスペクトルが分子量 $M_{e}$ の大き さの分子の運動モードによる時間まで連なるとすると， $\tau_{c}$ に対して，(8)式あるいは(14)式が得られる， $\tau_{m}$ に関 しては(i)の実験事実を用い，(9)式拉よび(15)式のように 仮定した。また， て は(5)式を用いて決定された。

$g_{N}$ は中間のスペクトル $H_{I}$ の存在の可能性を示す パラメータであり， hは $H_{B}$ の高さに関するパラメー タである。からみ合いによる分子網目の緩和に要する 時間は少なくともからみ合い点間が分子鎖の運動の時 間よりも長いと考光られ， $\tau_{l} \geq \tau_{c}$ の条件によってパラ メータ $h$ 数值はとりらる範囲が限定される。

(A)の場合, $h \leq 3.5$
(B)の場合, $h \leq 4$

3 粘度 $\eta$, 定常状態コンプライアンス $\boldsymbol{J}_{e}$ の計算

上記のモデルによる $\eta ， J e$ の計算結果は次のように なる。

(A)の場合,

$$
\begin{aligned}
& \eta=\frac{c R T}{M_{e}} \tau_{c}\left\{1+\left(1-g_{N}\right)(E-1)\right. \\
& \left.+\frac{g_{N}}{h} E^{3.5}\left[1-e^{h(1 / E-1)}\right]\right\} \\
& J_{e}=\frac{1}{3} \frac{M_{e}}{c R T} \frac{1+\left(1-g_{N}\right)\left(E^{3}-1\right)}{\left\{1+\left(1-g_{N}\right)(E-1)\right.} \\
& \frac{+\frac{3 g_{N}}{2 h} E^{7}\left[1-e^{2 h(1 / E-1)}\right]}{\left.+\frac{g_{N}}{h} E^{3.5}\left[1-e^{h(1 / E-1)}\right]\right\}^{2}}=\frac{1}{3} \frac{M_{e}}{c R T} A E
\end{aligned}
$$

$J_{e}$ の分子量依存性は $A(E)$ で, 濃度依存性は $A$ (E) $/ E^{2}$ で与兄られる.

(B)の場合,

$$
\begin{aligned}
\eta= & \frac{1.75 c R T}{M_{e}} \tau_{c}\left\{1+\left(1-g_{N}\right)\left(E^{1 / 2}-1\right)\right. \\
& \left.+\frac{g_{N}}{1.75 h} E^{3.5}\left(1-e^{1.75 h(1 / E-1) / 2}\right\}\right\}
\end{aligned}
$$

$$
\begin{aligned}
& J_{e}=\frac{1}{4(1.75)} \frac{M_{e}}{c R T} \frac{1+\left(1-g_{N}\right)\left(E^{2}-1\right)}{\left\{1+\left(1-g_{N}\right)\left(E^{1 / 2}-1\right)\right.} \\
& \frac{+\frac{2 g_{N}}{1.75 h} E^{7}\left[1-e^{1.75 h(1 / E-1)}\right]}{\left.+\frac{g_{N}}{1.75 h} E^{3.5}\left[1-e^{1.75 h(1 / E-1) / 2}\right]\right\}^{2}} \\
& =\frac{1}{4(1.75)} \frac{M e}{c R T} B(E)
\end{aligned}
$$

$J_{e}$ の分子量依存性は $B(E)$ で, 濃度依存性は $B(E)$ $/ E^{2}$ で与えられる。

\section{$4 \eta, J_{e}$ の数値計算}

パラメータ $g_{N}, h$ の值をそれぞれ $1 / 2,3.5$ あるい は 4 とした場合の $\eta, J_{e}$ に対する数值計算の結果を 


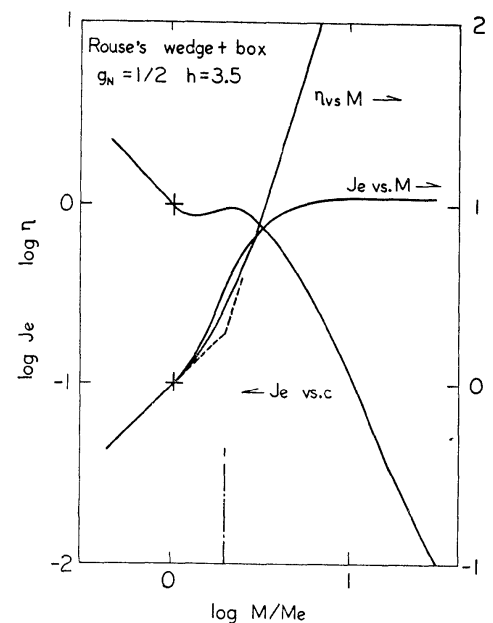

Fig. 2 Concentration dependence of $J_{e}$ and molecular weight dependence of $J_{e}$ and $\eta$, in the case of (A), with $g_{N}=1 / 2$ and $h=35$.

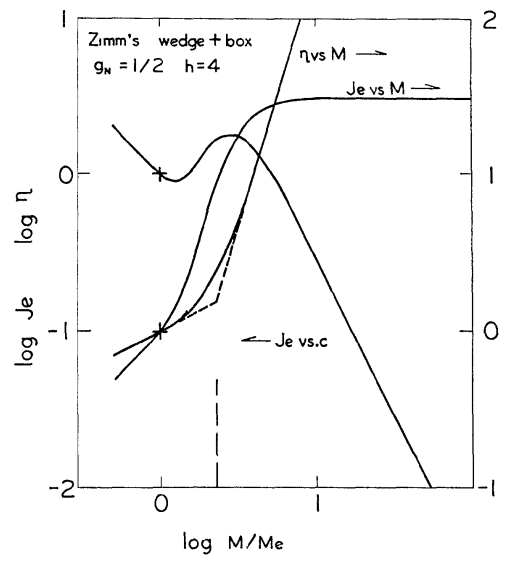

Fig 3 Concentration dependence of $J_{e}$ and molecular werght dependence of $J_{e}$ and $\eta$, in the case of (B), with $g_{N}=1 / 2$ and $h=4$

Fig. 2，3に示した。 Fig. 2，3 亿抒いて， $\log \eta$ 対 $\log$ $M$ の曲線は高分子量側で $\eta \propto M^{3.5}$ となり，(b)の挙動 をよく表わしている。亦たFig. 2 の同じ曲線は低分子 量側で $\eta \propto M$ となり(a)の結果に一致する。しかし $H_{W}$ に Zimm 理論によるスペクトルを用いた Fig. 3 の曲 線は $\eta \propto M^{1 / 2}$ となり，(a)と一致しない。 また $\log \eta$ 対 $\log M$ の曲線は $M$ の増加とともに(a)から(b)の挙動に移 る間, 徐々に変化し(d)の結果をよく表わしている。 こ れらの曲線から図に破線抢よび鎖線で示した通常の方 法で評価した $M_{c}$ の $M_{e}$ に対する比を Table I に示 した. $M_{c} / M_{e}$ の值は $g_{N}, h$ の值によって変化するが， $g_{N}$ にかかわらず hの值が大きい場合，従来考光られ ている 2 の值近いものである。

$\log J_{e}$ 対 $\log M$ の曲線は低分子量側で $J_{e} \propto M$, 高 分子量側で $J_{e} \propto M^{\circ}$ となり，先の間 $M$ の増加とともに 急激汇变化する。 Fig. 2,3 ともにこの曲線洔特
Table I. Variations of the ratio of critical molecular weight $M_{c}$ to entanglement spacing $M_{e}$ and the ratio of steady-state compliance $J_{e}$ to entanglement compliance $J_{e N}$ with the values of $g_{N}$ and $h$.

\begin{tabular}{|c|c|c|c|c|c|}
\hline \multicolumn{2}{|c|}{ For $(\mathrm{A})$} & \multirow{2}{*}{$\begin{array}{c}g_{N}=1 \\
J_{e} / J_{e N}\end{array}$} & \multicolumn{2}{|c|}{ For (A) } & \multirow{2}{*}{$\frac{g_{N}=1 / 2}{J_{e} / J_{e N}}$} \\
\hline$h$ & $M_{c} / M_{e}$ & & $h$ & $M_{c} / M_{e}$ & \\
\hline 1 & 14 & 0927 & 1 & 17 & 1012 \\
\hline 15 & 15 & 1080 & 15 & 18 & 1089 \\
\hline 2 & 16 & 1188 & 2 & 19 & 1211 \\
\hline 35 & 17 & 1680 & 35 & 21 & 1687 \\
\hline \multicolumn{2}{|c|}{ For (B) } & $g_{N}=1$ & \multicolumn{2}{|l|}{ For (B) } & $g_{N}=1 / 2$ \\
\hline$h$ & $M_{c} / M_{e}$ & $J_{e} / J_{e N}$ & $h$ & $M_{c} / M_{e}$ & $J_{e} / J_{e N}$ \\
\hline 1 & 16 & 0949 & 1 & 20 & ० 978 \\
\hline 1714 & 16 & 1071 & 1714 & 20 & 1093 \\
\hline 2285 & 17 & 1193 & 2285 & 21 & 1208 \\
\hline 4 & 20 & 1688 & 4 & 24 & 1725 \\
\hline
\end{tabular}

的な差異はなく、いずれも(e)，(f)の結果と一致する。 ただ Fig. 3 の曲線に打ける立ち上がり部分はFig. 2 に 比べてかなりこう配が大きい。

$\log J_{e}$ 対 $\log c$ の曲線は, Fig. 2, 3 のいずれに执い ても臨界濃度の若干高濃度側で極大を持ち，(h)の挙動 を定性的には上く表現している。Fig. 3 の曲線に执け る極大は Fig. 2 に比べて非常に鋭い，Fig. 2，3 の曲 線はいずれも低濃度側で $J_{e} \propto c^{-1}$, 高濃度側で $J_{e} \propto c^{-2}$ となり，(e)，(f)の結果に一致している.

パラメータ $g_{N}, h$ の值を変化させた場合の $\log J_{e}$ 対 $\log c$ の曲線の変化をFig. 4，5 亿示した. Fig.4, 5 いずれの場合も $g_{N}$ を小さく，hを大きくした場合， $J_{e}$ の極大値が若干低下し, 極大に達する濃度が若干高 濃度側飞移動するが，曲線が形自体には極端な変化は 生じない。

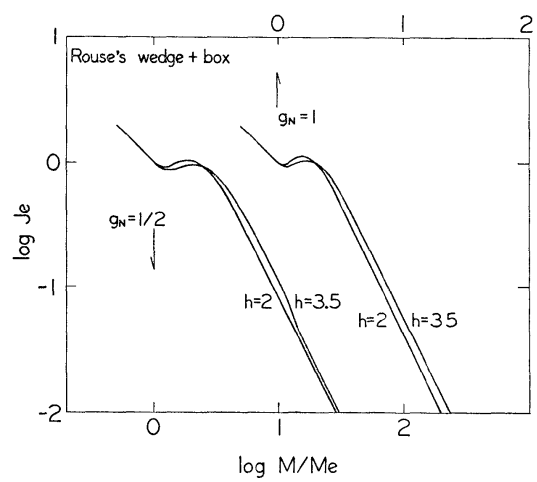

Fig. 4. Variation of concentration dependence of $J_{e}$ with the values of $g_{N}$ and $h$ in the case of (A) 


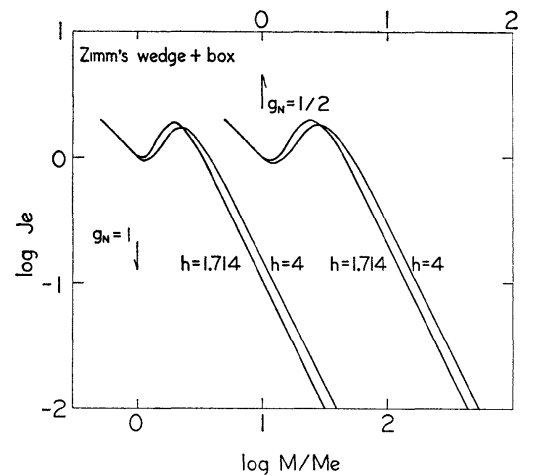

Fig. 5. Variation of concentration dependence of $J_{e}$ with the values of $g_{N}$ and $h$ in the case of (B)

\section{5 貯藏弾性率 $\boldsymbol{G}^{\prime}(\boldsymbol{\omega})$, 損失弾性率 $G^{\prime \prime}(\boldsymbol{\omega})$ の数值計算}

くさび形スペクトルに分離した箱形スペクトルを加 えた形の緩和スペクトルから導かれる $G^{\prime}, G^{\prime \prime}$ の式は

“箱”の高さ，幅に関係なく普遍的なるのであるが， まだ文献に示されていないので，Appendix に記入し て拉く.

パラメータ $g_{N}, h$ の数值計算の組み合わせを変え

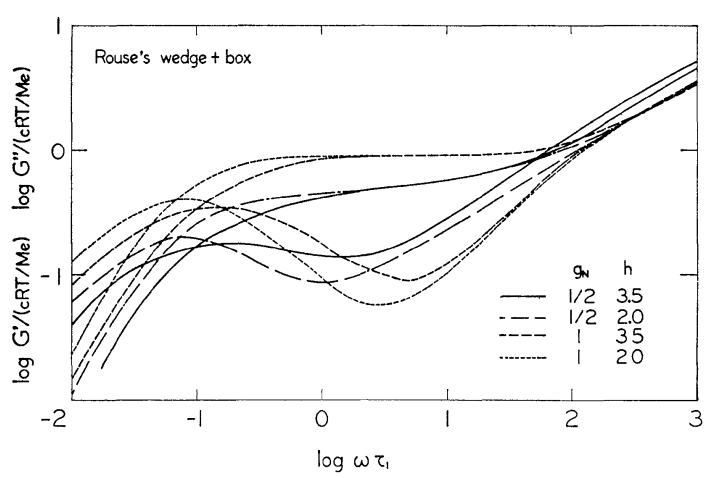

F1g. 6. Storage modulus $G^{\prime}$ and loss modulus $G^{\prime \prime}$ with various values of $g_{N}$ and $h$, in the case of (A).

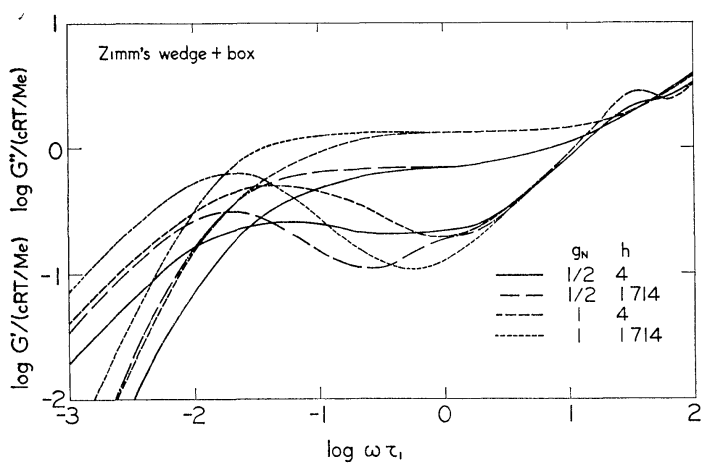

Fig. 7. Storage modulus $G^{\prime}$ and loss modulus $G^{\prime \prime}$ with various values of $g_{N}$ and $h$, in the case of (B).
た場合について， $G^{\prime} ， G^{\prime \prime}$ の数值計算の結果を Fig. 6 , 7 に示した。、いずれの曲線に括いても $E=M / M_{e}$ の值 は10である。これらの曲線には $g_{N}, h$ の值にかかわ らず，ゴム状平坦領域で $G^{\prime \prime}$ の極小が存在し，(m)の実 験結果を定性的には表現しらる。乙かし $g_{N}=1$ に, $h$ を小さした場合, ゴラ状平坦領域に生じる $G^{\prime \prime}$ の 谷は実験的に見いだされているものに比べて極端に深 い.これは $\tau_{c} \sim \tau_{l}$ 間のスペクトルの完全な欠除によ っており，この点は $h$ を大きくし， $g_{N}$ を $1 / 2$ とした 場合，すなわち $H_{B}$ の高さを低くし，中間のスペクト ル $H_{I}$ を加えた場合に改善され，Fig. $6 ， 7$ において 実線で示した曲線に括ける $G^{\prime \prime}$ の極小は実験結果に比 ベてほぼ妥当なものである。

ゴム状平坦領域に㨟汀る $G^{\prime}$ の高さから，からみ合 いコンプライアンスと呼ばれる量 $J_{e N}$ を求めることが でさる。この $J_{e N}$ に詨する $J_{e}$ の比, $J_{e} / J_{e N}$ の值を Table I に示した. $J_{e} / J_{e N}$ の值は $g_{N}$ にはほとんど よらず，(A)，(B)いずれの場合も $h$ が大さいときには約 1.7 であり，hが1のときには約 1 である。実験的に は， $J_{e} / J_{e N}$ は2 2 程度であるといわれて拉り，これ に比べると計算值は若干小さいが， $h$ が大きい場合の $J_{e} / J_{e N}=1.7$ といら值は滦浽当であるとい光る。

\section{Appendix}

(A) Rouse's Wedge + Box

$$
\begin{aligned}
& G^{\prime}(\omega) \frac{M_{e}}{c R T}=\frac{t}{4 \sqrt{2}}\left[\log \frac{t^{2}-\sqrt{2} t+1}{t^{2}+\sqrt{2} t+1}+2 \tan ^{-1} \frac{\sqrt{2} t}{1-t^{2}}\right] \\
& +\left(\frac{g_{N}}{2 h}\right) \log \frac{1+t^{4} E^{7}}{1+t^{4} E^{7} e^{2 h(1 / E)}} \\
& +\left(1-g_{N}\right) \frac{t}{4 \sqrt{2}}\left[\log \frac{t^{2} E^{2}-\sqrt{2} t E+1}{t^{2} E^{2}+\sqrt{2} t E+1}\right. \\
& +2 \tan ^{-1} \frac{\sqrt{2} t E}{1-t^{2} E^{2}}-\log \frac{t^{2}-\sqrt{2} t+1}{t^{2}+\sqrt{2} t+1} \\
& \left.-2 \tan ^{-1} \frac{\sqrt{2} t}{1-t^{2}}\right] \\
& G^{\prime \prime}(\omega) \frac{M_{e}}{c R T}=\frac{t}{4 \sqrt{2}}\left[\log _{t^{2}-\sqrt{2}+\sqrt{2} t+1}+2 \tan ^{-1} \frac{\sqrt{2} t}{1-t^{2}}\right] \\
& +\left(\frac{g_{N}}{h}\right)\left[\tan ^{-1}\left(t^{2} E^{3.5}\right)\right. \\
& \left.-\tan ^{-1}\left\{t^{2} E^{3.5} e^{h(1 / E-1)}\right\}\right] \\
& +\left(1-g_{N}\right) \frac{t}{4 \sqrt{2}}\left[\log \frac{t^{2} E^{2}+\sqrt{2} t E+1}{t^{2} E^{2}-\sqrt{2} t E+1}\right. \\
& +2 \tan ^{-1} \frac{\sqrt{2} t E}{1-t^{2} E^{2}}-\log \frac{t^{2}+\sqrt{2} t+1}{t^{2}-\sqrt{2} t+1} \\
& \left.-2 \tan ^{-1} \frac{\sqrt{2} t}{1-t^{2}}\right]
\end{aligned}
$$

Here $t=\sqrt{\omega \tau_{1}} / E$

(B) Zimm's Wedge + Box

$$
\begin{aligned}
G^{\prime}(\omega) \frac{M_{e}}{c R T}= & \frac{t^{2}}{4} \log \left|t^{2}-\sqrt{3} t+1\right|-\frac{t^{2}}{2} \log \left|t^{2}+1\right| \\
& +\frac{t^{2}}{4} \log \left|t^{2}+\sqrt{3} t+1\right|
\end{aligned}
$$




$$
\begin{aligned}
& -\frac{\sqrt{3}}{2} t^{2} \tan ^{-1}(\sqrt{3}-2 t) \\
& -\frac{\sqrt{3}}{2} t^{2} \tan ^{-1}(\sqrt{3}+2 t) \\
& +\frac{3 g_{N}}{3.5 h} \log \frac{1+t^{6} E^{7}}{1+t^{6} E^{7} e^{1.75 h(1 / E-1)}} \\
& +\left(1-g_{N}\right) t^{2}\left[\frac{1}{4} \log \left|t^{2} E-\sqrt{3} t \sqrt{E}+1\right|\right. \\
& -\frac{1}{2} \log t^{2} E+1\left|+\frac{1}{4} \log \right| t^{2} E \\
& +\sqrt{3} t \sqrt{E}+1 \mid-\frac{\sqrt{3}}{2} \tan ^{-1}(\sqrt{3}-2 t \sqrt{\bar{E}}) \\
& -\frac{\sqrt{3}}{2} \tan ^{-1}(\sqrt{3}+2 t \sqrt{E}) \\
& -\frac{1}{4} \log \left|t^{2}-\sqrt{3} t+1\right|+\frac{1}{2} \log \left|t^{2}+1\right| \\
& -\frac{1}{4} \log \left|t^{2}+\sqrt{3} t+1\right| \\
& +\frac{\sqrt{3}}{2} \tan ^{-1}(\sqrt{3}-2 t) \\
& \left.+\frac{\sqrt{3}}{2} \tan ^{-1} \cdot(\sqrt{3}+2 t)\right] \\
& G^{\prime \prime}(\omega) \frac{M_{e}}{c R T}=\frac{\sqrt{3}}{4} t^{2} \log \frac{t^{2}+\sqrt{3} t+1}{t^{2}-\sqrt{3} t+1}+\frac{t^{2}}{2} \tan ^{-1} \frac{t}{1-t^{2}} \\
& +t^{2} \tan ^{-1} t+\frac{3 g_{N}}{1.75 h}\left[\tan ^{-1}\left(t^{3} E^{3.5}\right)\right. \\
& \left.-\tan ^{-1}\left\{t^{3} E^{3.5} e^{1.75 h(1 / E-1) / 2}\right\}\right] \\
& +\left(1-g_{N}\right) t^{2}\left[\frac{\sqrt{3}}{4} \log \frac{t^{2} E+\sqrt{3} t \sqrt{E}+1}{t^{2} E-\sqrt{3} t \sqrt{E}+1}\right. \\
& +\frac{1}{2} \tan ^{-1} \frac{t \sqrt{E}}{1-t^{2} E}+\tan ^{-1}(t \sqrt{E}) \\
& -\frac{\sqrt{3}}{4} \log \frac{t^{2}+\sqrt{3} t+1}{t^{2}-\sqrt{3} t+1}-\frac{1}{2} \tan ^{-1} \frac{t}{1-t^{2}} \\
& \left.-\tan ^{-1} t\right]
\end{aligned}
$$

Here $t=\left(\omega \tau_{1}\right)^{1 / 3} / E^{1 / 2}$.

（昭和46年10月21日 第19回レオロジー講演会にて講演）

1) Ferry, J.D., "Viscoelastic Properties of Polymers" 2nd ed. (1970) New York N. Y., Wily

2) Berry, G.C., and T. G Fox, Adv. Polymer Sc1, 5, 261 (1968).

3) Kotaka, T, and K. Osaki, J. Polymer Sc1., Part C, No. 15, 453 (1966).

4) Holmes, L A., and J D Ferry J. Polymer Sc1., Part C, No 23, 291 (1968).

5) Einaga, Y, K Osakı, M. Kurata, and M. Tamura Macromolecules, 4, 87 (1971).

6) Onog1, S., T. Masuda, and K. Kitagawa, Macromolecules, 3, 109 (1970).

7) Tobolsky, A V, J. J Aklonis, and G. Akoval1, J. Chem. Phys., 42, 723 (1965).

8) Fuıımoto, T., N. Ozakı, and M. Nagasawa., J. Polymer Sc1., Part A-2, 129 (1968).

9) Prest, W M., J. Polymer Sc1., Part A-2, 8, 1897 (1970).

10) Prest, W. M., R S. Porter, and J. M. O’Re1lly J. Applied Polymer Sc1, 14, 2697 (1970).

11) Janeschitz-Kriegle, Adv. Polymer Sc1., 6, 170 (1969).

12) Graessley, W W., and L. Segal, Macromolecules, 2, 49 (1969).

13) Einaga, Y., K Osakı, M. Kurata, and M. Tamura in Preparation.

14) Rouse, P. E., J. Chem. Phys., 21, 1272 (1953).

15) Zimm, B H., J. Chem. Phys., 24, 269 (1956).

(452頁より)

239. Rheological properties of two dimensional surface films, J. V. Boyd, 153.

240. Rheological properties of thin gelatin films, S. Kislalioglu, E. Shotton, S. Davis, B. Warburton, 158.

241. Numerical calculation of storage and loss modulus from stress relaxation data for linear viscoelastic materials, F. J. Schwarzl, 165.

242. Some investigations of melt fracture, J. L. den Otter, 200.

243. The statistical interpretation of viscoelasticity, N.A. Brunt, 214.

244. Der Einfluss von Molekulargewicht und Molekulargewichtsverteilung auf die viskoelastischen Eigenschaften von Polystyrolschmelzen, A. Zose1, 215.

245. Untersuchung rheologischer Vorgänge beim Erstarren von Gelatine, W. Hoffmann, 225.

246. Dehnungsverhalten von Polyäthylen-Schmelzen, J. Meissner, 230.

247. Eine Strukturtheorie des rheologischen Verhaltens hochpolymerer Flussigkeiten, R. -K. Takserman, 243.

248. Behavior of deformable particles in laminar flow, W. Philippoff, 250.

249. On stress distribution in flows of Viscoelastic Fluids through Ducts with Porous Walls, R. K. Bhatnagar, 257.

(468頁へ) 